\title{
Characterization of an Immediate-Early Gene Induced in Adherent Monocytes That Encodes IkB-like Activity
}

\author{
Stephen HasklII, "†‡ Amer A. Beg, "\$ S. Mark Tompkins, " \\ John S. Morris," Andrew D. Yurochko," \\ Adam Sampeon-Johannes, II Krishna Mondal," \\ Peter Ralph,ll and Albert S. Baldwin, Jr. "\$\# \\ * Lineberger Comprehensive Cancer Center \\ tDepartment of Obstetrics and Gynecology \\ ‡Department of Microbiology and Immunology \\ SDepartment of Biology \\ \#Curriculum in Genetics \\ University of North Carolina at Chapel Hill \\ Chapel Hill, North Carolina 27599 \\ IDepartment of Cell Biology \\ Cetus Corporation \\ Emeryville, California 94608
}

\section{Summary}

We have cloned a group of cDNAs representing mANAs that are rapidly induced following adherence of human monocytes. One of the induced transcripts (MAD-3) encodes a protein of 317 amino acids with one domain containing five tandem repeats of the cdc10/ ankyrin motif, which is $60 \%$ similar (46\% identical) to the ankyrin repeat region of the precursor of NF-KB/ KBF1 p50. The C-terminus has a putative protein kinase C phosphorylation site. In vitro translated MAD-3 protein was found to specifically inhibit the DNAbinding actlvity of the p50/p65 NF-KB complex but not that of the p50/p50 KBF1 factor or of other DNAbinding proteins. The MAD-3 CDNA encodes an IKBIlke protein that is likely to be involved in regulation of transcriptional responses to NF-KB, including adhesion-dependent pathways of monocyte activation.

\section{Introduction}

NF- $\mathrm{B}$ is an important transcription factor originally characterized as an lgk enhancer binding protein (Sen and Baltimore, 1986). In addition, binding sites for NF-kB are present in the regulatory regions of certain cytokine genes, the interleukin-2 (IL-2) receptor gene, class I and II histocompatibility antigen genes, an acute phase response gene, and several viral enhancers, including HIV-1 (Lenardo and Baltimore, 1989; Shimizu et al., 1990; Liebermann and Baltimore, 1990; Fan and Maniatis, 1989; Visvanathan and Goodbourn, 1989; Lenardo et al., 1989; Böhnlein et al., 1988; Baldwin and Sharp, 1988; Blanar et al., 1989; Ron et al., 1990; Nabel and Baltimore, 1987). These sites appear to be critical for appropriate regulated or cell type-specific gene expression. Stimulation by a number of agents including PMA, IL-1 $\beta$, TNF $\alpha$, and lipopolysaccharide results in the induction of nuclear NF-кB DNA-binding activity (Sen and Baltimore, 1986; Osborn et al., 1989; Israël et al., 1989; Lowenthal et al., 1989; Shirakawa et al., 1989; Lenardo and Baltimore, 1989). NF-kB is a complex of two proteins, p50 and p65 (Baeuerle and Baltimore, 1989). The cDNA encoding the p50 DNAbinding subunit of NF- $\mathrm{B}$ has been cloned, and the predicted protein was shown to be related to the Drosophila dorsal maternal effect gene and to the c-rel protooncogene product (Ghosh et al., 1990; Kieran et al., 1990; Bours et al., 1990; Meyer et al., 1991). Furthermore, it appears that the p50 DNA-binding subunit is processed from a $105 \mathrm{kd}$ precursor protein that has six C-terminal repeats of the ankyrin consensus sequence (Kieran et al., 1990; Ghosh et al., 1990). Ankyrins are known to constitute a family of proteins that regulate interactions between a variety of membrane structures and the cytoskeleton (Lux et al., 1990). Proteins bearing multiple repeats of these structures are thus highly likely to be associated with receptors and the cytoskeleton. The DNA-binding activity KBF1 is the homodimer of the NF-KB p50 DNA-binding subunit (Kieran et al., 1990). The cloning of the cDNA encoding the p65 NF-KB subunit has recently been reported and the predicted protein sequence demonstrates homology to c-rel as well (Nolan et al., 1991; Ruben et al., 1991).

In many cells, NF- $\mathrm{BB}$ is localized in the cytoplasm where it is associated with a $36 \mathrm{kd}$ inhibitor protein, I $\mathrm{B}$ (Baeuerle and Baltimore, 1988a, 1988b; Ghosh and Baltimore, 1990; Zabel and Baeuerle, 1990). The p65 NF-кB subunit appears to be the target of interaction of I $\mathrm{KB}$ (Baeuerle and Baltimore, 1989; Ghosh and Baltimore, 1990; Urban and Baeuerle, 1990; Nolan et al., 1991). Evidence has been presented that phosphorylation of IKB blocks its ability to inhibit NF-kB DNA-binding activity, since protein kinase $C$ (PKC) and several other kinases activate NF-KB DNAbinding activity in vitro (Ghosh and Baltimore, 1990; Shirakawa and Mizel, 1989).

Adherence of monocytes to plastic results in the rapid induction of many known cytokines; including IL-1, TNFa, colony stimulating factor-1, and the down-regulation of other constitutively expressed receptors and mediators including c-fms and lysozyme (Haskill et al., 1988; Eierman et al., 1989). We have described the cloning of a series of novel CDNA clones from a monocyte library constructed from monocytes adhered on plastic for $30 \mathrm{~min}$ (Sporn et al., 1990; Haskill et al., 1990, 1991). We demonstrate here that another unique cDNA clone, MAD-3, encodes a protein that appears by several criteria to be an IKB-like molecule.

\section{Results}

We have studied gene expression in monocytes adhering to different substrates as models of mononuclear phagocyte maturation and of inflammation (Haskill et al., 1988; Eierman et al., 1989). One gene, MAD-3, is expressed early after monocyte adherence to plastic. By Northern analysis the transcripts are $1.6 \mathrm{~kb}$ in size and $0.04 \%$ abundant in $\mathbf{3 0}$ min plastic-adherent monocytes (Sporn et al., 1990). Adherence resulted in at least an 80 -fold induction and expression was transient: levels returned to baseline within $8 \mathrm{hr}$ (data not shown). Inclusion of cycloheximide 
A

TGCCGCCGTCCCGCCCGCCAGCGCCCCAGCGAGGAAGCAGCGCGCAGCCCGCGGCCCAGC GCACCCGCAGCAGCGCCCGCAGCTCGTCCGCGCCATGTTCCAGGCGGCCGAGCGCCCCCA $M \quad F \quad Q \quad A \quad A \quad E$ R $P$ Q GGAGTGGGCCATGGAGGGCCCCCGCGACGGGCTGAAGAAGGAGCGGCTACTGGACGACCG $\begin{array}{llllllllllllllllllll}\mathbf{E} & \mathbf{W} & \mathbf{A} & \mathbf{M} & \mathbf{E} & \mathbf{G} & \mathbf{P} & \mathbf{R} & \mathbf{D} & \mathbf{G} & \mathbf{L} & \mathbf{K} & \mathbf{K} & \mathbf{E} & \mathbf{R} & \mathbf{L} & \mathbf{L} & \mathbf{D} & \mathbf{D} & \mathbf{R}\end{array}$ CCACGACAGCGGCCTGGACTCCATGAAAGACGAGGAGTACGAGCAGATGGTCAAGGAGCI

$\begin{array}{llllllllllllllllllll}H & D & S & G & L & D & S & M & K & D & \mathbf{B} & \mathbf{B} & \mathbf{Y} & \mathbf{B} & \mathbf{O} & \mathbf{H} & \mathbf{V} & \mathbf{K} & \mathbf{E} & \mathbf{L}\end{array}$ GCAGGAGATCCGCCTCGAGCCGCAGGAGGTGCCGCGCGGCTCGGAGCCCTGGAAGCAGCA

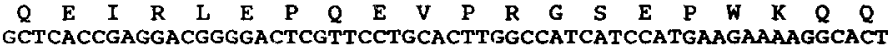

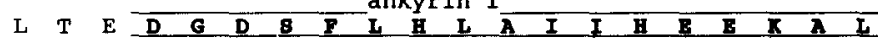
GACCATGGAAGTGATCCGCCAGGTGAAGGGAGACCTGGCCTTCCTCAACTTCCAGAACAA

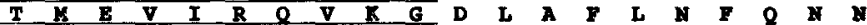
CCTGCAGCAGACTCCACTCCACTTGGCTGTGATCACCAACCAGCCAGAAATTGCTGAGGC ankyrin II

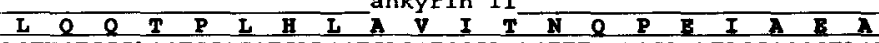
ACTTCTGGGAGCTGGCTGTGATCCTGAGCTCCGAGACTTTCGAGGAAATACCCCCCTACA

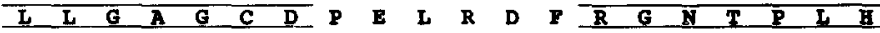
$\frac{L}{\text { CCTTGCCTGTGAGCAGGGCTGCCTGGCCAGCGTGGGAGTCCTGACTCAGTCCTGCACCAC }}$ ankyrin III

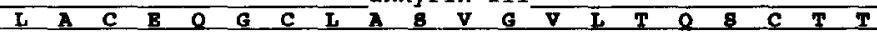
CCCGCACCTCCACTCCATCCTGAAGGCTACCAACTACAATGGCCACACGTGTCTACACTT

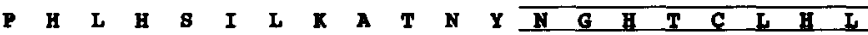
AGCC'I'TATCCATGGCI'IACCTGGGCATCG'I'GGAGCTTPTGGITCCITGGGTGCTGATGT ankyrin IV

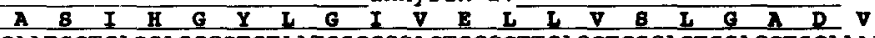
CAATGCTCAGGAGCCCTGTAATGGCCGGACTGCCCTTCACCTCGCAGTGGACCTGCAAAA ankyrin $\mathrm{v}$

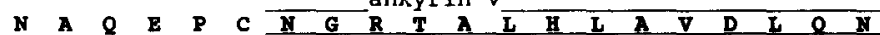
TCCTGACCTGGTGTCACTCCTGTTGAAGTGTGGGGCTGATGTCAACAGAGTTACCTACCA

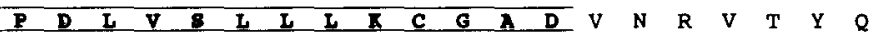

GGGCTATTCTCCCTACCAGCTCACCTGGGGCCGCCCAAGCACCCGGATACAGCAGCAGCT $\begin{array}{llllllllllllllllllll}G & Y & S & P & Y & Q & L & T & W & G & \mathbf{R} & \mathbf{P} & \mathbf{B} & \mathbf{T} & \mathbf{R} & \mathrm{I} & \mathbf{Q} & \mathbf{Q} & \mathbf{Q} & \mathbf{L}\end{array}$ GGGCCAGCTGACACTAGAAAACCTTCAGATGCTGCCAGAGAGTGAGGATGAGGAGAGCTA $\begin{array}{llllllllllllllllllll}G & Q & L & T & L & E & N & L & Q & M & L & P & E & S & E & D & E & E & S & Y\end{array}$ TGACACAGAGTCAGAGTTCACGgAGTTCACAGAgGACGAGCTGCCCTATGATGACTGTGT

$\begin{array}{llllllllllllllllllll}D & \mathbf{T} & \mathbf{E} & \mathbf{S} & \mathbf{E} & \mathbf{F} & \mathbf{T} & \mathbf{E} & \boldsymbol{F} & \mathbf{T} & \mathbf{E} & \mathbf{D} & \mathbf{E} & \mathbf{L} & \mathbf{P} & \mathbf{Y} & \mathbf{D} & \mathbf{D} & \mathbf{C} & \mathbf{V}\end{array}$ GTTTGGAGGCCAGCGTCTGACGTTATGAGTGCAAAGGGGCTGAAAGAACATGGACTTGTA F G G $Q R$ R L T L

TATTTGTACAAAAAAAAAGTT'TTATTTTTCTAAAAAAAGAAAAAAGAAGAAAAAMTTTA AGGGTGTACTTATATCCACAC'TGCACACTGCCTAGCCCAAAACGTCTTATTGTGGTAGGA TCAGCCCTCATTTTGTTGCTTTTGTGAACTTTTTGTAGGGGACGAGAAAGATCATTGAAA TTCTGAGAAAACTTCTTTTAAACCTCACCTTTGTGGGGTTTTTGGAGAAGGTTATCAAAA ATTTCATGGAAGGACCACATTTTATATTYTTGTGCTTCGAGTGACTGACCCCAGTGGTA TCCTGTGACATGTAACAGCCAGGAGTGTTAAGCGTTCAGTGATGTGGGGTGAAAAGTTAC TACCTGTCAAGGTTTGTGTTACCCTCCTGTAAATGGTGTACATAATGTATTGTTGGTAAT TATTTTGGTACTTTTATGATGTATATTTRTTAAAGAGATTTTTACAAATG
Figure 1. Nucleotide and Amino Acid Sequence and Hydrophobicity Predictions for the MAD 3 cDNA

(A) Nucleic acid and predicted protein sequence of cDNA clone MAD-3. The DNA sequence and the amino acid transtation predicted by the DNA sequence are also shown. The $1.6 \mathrm{~kb}$ size of the clone is close to that predicted from the transcript size on Northern analysis. The consensus tyrosine phosphorylation site and the possible phosphatidylinositol-3 kinase binding domain is underlined, the predicted PKC phosphorylation site is overlined, and the three ATTTA motifs are underlined and typed in bold. The ankyrin repeat domain (Lux et al., 1990) is typed in bold, and individual repeats are overlined and underlined.

(B) Hydrophilicity/hydrophobicity predictions for the proposed MAD-3 protein. The limits of the five ankyrin repeats are overlined and the location of individual ones are marked. The predicted phosphatidylinositol-3 kinase binding domain and the apparent PKC target sequences are also overlined. The plot was derived with the University of Wisconsin GCG program PEPPLOT

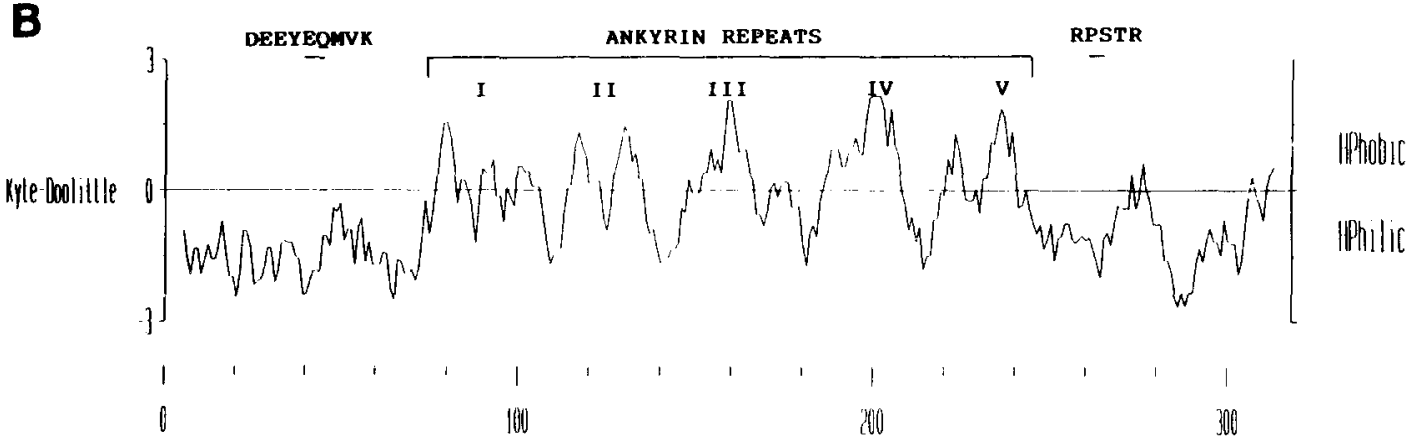

during adherence enhanced slightly the levels of mRNA, demonstrating that MAD-3 is an immediate-early gene induced by monocyte adherence (data not shown).

\section{Structure of MAD-3 CDNA}

A full-length cDNA of MAD-3 was cloned from a library constructed from RNA pooled from fresh neutrophils and collagen-adherent monocytes. The probe was a $350 \mathrm{bp}$
cDNA isolated from the original $\lambda$ gt 10 library used to define adherence-induced cDNA clones (Sporn et al., 1990). The sequence of the MAD-3 CDNA of 1550 bp is shown in Figure $1 \mathrm{~A}$. It extends 94 bp $5^{\prime}$ of a Kozak consensus sequence (Kozak, 1989) for the predicted start of translation. The $3^{\prime}$ untranslated region contains three ATTTA motifs that usually signal rapid turnover of the mRNA (Caput et al., 1986; Shaw and Kamen, 1986). A poly(A) tail begins at the end of bp 1550. 


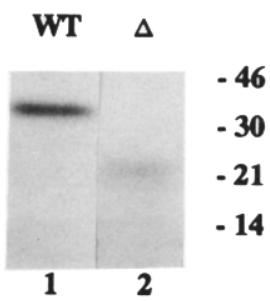

B
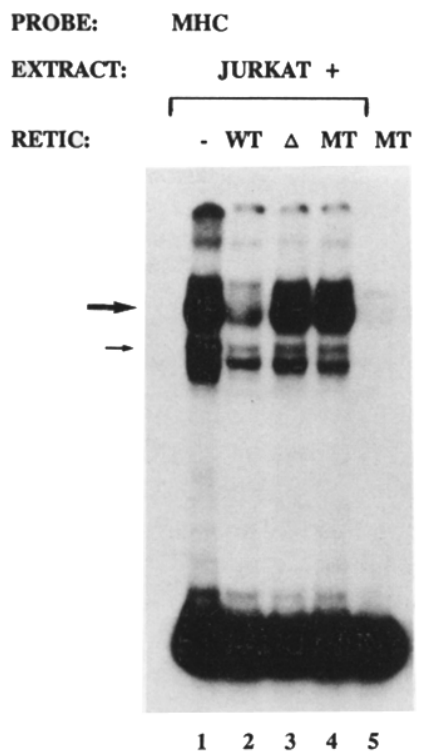

C
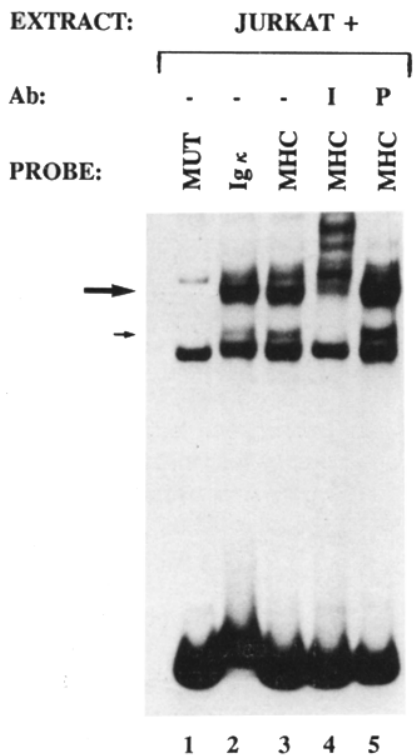

Figure 2. In Vitro Transcribed MAD-3 mANA Translates a 36-38 kd Protein with Properties of $1 \kappa B$

(A) $10 \%$ SDS-polyacrylamide gel analyzing reticulocyte lysates programmed with in vitro transcribed MAD-3 mRNA (lane 1, WT) or with MAD-3 mRNA transcribed from an Accl-digested plasmid (lane 2, $\Delta$ ).
The predicted polypeptide specified by the open reading frame is composed of 317 amino acids and should encode a protein of approximately $34 \mathrm{kd}$. Secondary structure predictions suggest that the protein is arranged in three domains (Figure 1B). The $\mathrm{N}$-terminal domain contains a hydrophilic stretch of 72 amino acids, which is marked by a consensus sequence (DEEYEQMVK) for tyrosine phosphorylation and is similar to the potential binding site of the phosphatidylinositol-3 kinase (amino acids 39-47) (Cantley et al., 1991). The C-terminal domain contains two regions of interest. One is a consensus sequence for PKC phosphorylation (RPSTR) (amino acids 260-264) (Noland et al., 1989). The other is a region rich in PEST residues (amino acids 264-314), which have been associated with rapid protein turnover (Rogers et al., 1986). The internal domain (amino acids 73-242) consists of five tandem repeats of the ankyrin consensus sequence (Lux et al., 1990 ). This region was found to be $60 \%$ similar ( $46 \%$ identity) to the homologous ankyrin repeat region of the NF-кB/ KBF1 precursor (Ghosh et al., 1990; Kieran et al., 1990). The other domains of MAD-3 were dissimilar to NF-KB/ KBF1.

\section{MAD-3 Encodes a 36-38 kd Protein with Properties of IKB}

The presence of a consensus sequence for PKC phosphorylation, the predicted $34 \mathrm{kd}$ size of the expressed protein, and the homology with the precursor of NF-kB/KBF1 suggested the possibility that MAD-3 encodes an IKB-like protein. To test this hypothesis the full-length MAD-3 CDNA sequence was cloned into the expression plasmid pcDNA 1 and RNA was transcribed using SP6 RNA polymerase. Since the reticulocyte lysate used for translation contained an endogenous NF-kB-like activity (data not shown), the Iysates were depleted for this activity using a DNA affinity matrix specific for NF- $k$ B. These NF- $k$ B-depleted reticulocyte lysates demonstrated virtually no major histocompatibility complex (MHC) class I enhancer binding activity (Figure 2B, lane 5). The reticulocyte lysates were then used to

Protein was labeled with [35]methionine. The mobilities of prestained molecular weight markers are shown.

(B) Gel mobility shift analyzing programmed reticulocyte lysates and nuclear extracts of PMA- and PHA-treated Jurkat T cells. For all lanes the class I MHC enhancer probe was used. The following protein sources were used: nuclear extracts of stimulated Jurkat $\mathrm{T}$ cells (lane 1), Jurkat extracts plus MAD-3 programmed lysates (lane 2, WT), Jurkat extracts plus lysates translated with mRNA from the Accl-deleted construct (lane $3, \Delta$ ), Jurkat extracts plus mock-translated reticulocyte lysates (lane 4, MT), and mock-translated reticulocyte lysates alone (lane 5, MT). The large arrow indicates the mobility of the NF-KB-DNA complex, and the small arrow indicates the mobility of the KBF1-DNA complex.

(C) Gel mobility shift assay characterizing the nuclear extracts of the stimulated Jurkat $T$ cells. The following protein sources were used: extracts of stimulated Jurkat $T$ cells (lanes 1-5) plus either antiserum to the p50 DNA-binding subunit of NF-KB (lane 4, I indicates immune antiserum) or preimmune ( $P$ ) serum (lane 5 ). The DNA probes are as indicated above the figure: MUT (MHC double point mutant probe), IgK, and $\mathrm{MHC}$ (class I MHC enhancer probe). The large arrow indicates the mobility of the NF*kB-DNA complex, and the small arrow indicates the mobility of the KBF1-DNA complex. 
translate either full-length MAD-3 mRNA or mRNA derived from an Accl digest of the cDNA or were mock translated. Accl cuts the MAD-3 CDNA at the position corresponding to amino acid 186 in the fourth ankyrin repeat. The in vitro translated products, labeled with $\left[{ }^{35}\right.$ S]methionine, were electrophoresed on a $10 \%$ SDS-polyacrylamide gel. As predicted from the cDNA, the full-length MAD-3 mRNA and the mRNA from the Accl-digested plasmid revealed approximately 36 and $22 \mathrm{kd}$ proteins (Figure 2A, lanes 1 and 2).

The MAD-3 translation products were then tested in a gel mobility shift assay for their ability to inhibit NF-кB activity. A class I MHC enhancer sequence (TGGGGATTCCCCA), previously demonstrated to bind NF- $\mathrm{B}$ (Baldwin and Sharp, 1988), was used as a DNA-binding probe. We chose to analyze whether NF-KB activity in Jurkat $T$ cells stimulated with phytohemagglutinin (PHA) and phorbol 12-myristate 13-acetate (PMA) would be inhibited by the MAD-3 protein. The induction of NF-KB in these cells has been well documented (Nabel and Baltimore, 1987; Böhnlein et al., 1988), and, furthermore, there is an activity with properties of KBF1 in nuclear extracts of stimulated cells. As noted below, the DNA-protein complexes indicated by the arrows (Figure 2) appear by various criteria to be $N F-K B$ and KBF1. Addition of the MAD-3 programmed lysates inhibited the DNA-binding activity associated with the slower NF-kB-DNA complex (indicated by the large arrow, Figure 2B, lane 2) in the stimulated Jurkat $T$ nuclear extracts and only weakly affected the factor associated with the faster moving KBF1-DNA complex (indicated by the small arrow, Figure 2B, lane 2). Addition of either lysates programmed with the deleted mRNA or mockIranslated lysates did not affect DNA-binding activity of either complex (Figure 2B, lanes 3 and 4).

To further characterize the DNA-binding activities in the nuclear extracts of the PMA- and PHA-stimulated Jurkat cells, several assays were performed. We first demonstrated that the two activities identified by the arrows are specific for the MHC enhancer probe, as they do not inter- act with a double point mutated probe (Figure 2C, lane 1). We have previously shown that this mutant probe (TGCGGATTCCCGA) is not bound by NF-KB (Baldwin and Sharp, 1988). The factors associated with the slower and faster complexes interact equally well with $\lg \kappa$ and class I MHC enhancer probes (Figure $2 \mathrm{C}$, lanes 2 and 3), consistent with these activities being NF-KB and KBF1. Finally, the two DNA-protein complexes are recognized by antibodies against the p50 subunit of NF- $\mathrm{BB}$ (Figure $2 \mathrm{C}$, lane 4) but not by preimmune serum (Figure $2 \mathrm{C}$, lane 5 ). Thus, the MAD-3 protein strongly inhibits an authentic NF- $\kappa B$ activity from stimulated Jurkat $T$ cells and may inhibit the Jurkat KBF1 activity very weakly.

To demonstrate that the observed inhibition is specific for the NF- $\kappa B$ activity, we analyzed the effect of the MAD-3 protein on other characterized DNA-binding proteins (Figure $3 A$ ). MAD-3 did not inhibit the DNA-binding activity of the major late transcription factor (Carthew et al., 1985; also known as USF), the Oct-1 factor (Singh et al., 1986), or H2TF1, a class I MHC enhancer binding factor (Baldwin and Sharp, 1987). We next analyzed whether NF-kB from another cell source would be inhibited by the translated MAD-3 protein. NF- $K B$ from nuclear extracts of freshly isolated monocytes was inhibited by the MAD-3 protein, but the KBF1 activity found in these cells was unaffected (Figure $3 B$ ). Both the NF-KB and KBF1 activities in these extracts are recognized by antibodies to the $p 50$ NF- $K B$ subunit (data not shown). Thus, the MAD-3 protein is highly specific for NF- $\mathrm{BB}$ from several cell sources and has little or no effect on KBF1 DNA-binding activity (Figures 2B and 3B). These results are consistent with the observation that I $\mathrm{B}$ interacts with the $65 \mathrm{kd}$ subunit of NF-KB (Baeuerle and Baltimore, 1989; Ghosh and Baltimore, 1990; Urban and Baeuerle, 1990; Nolan et al., 1991), which is absent in KBF1 (Kieran et al., 1990). We therefore conclude that the MAD-3 translation product specifically inhibits NF-KB DNA-binding activity and does not inhibit the DNA-binding activity of KBF1, major late transcription factor, Oct-1, or H2TF1.
A

RETIC:

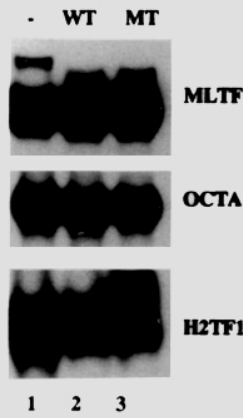

B

RETIC: - MT WT

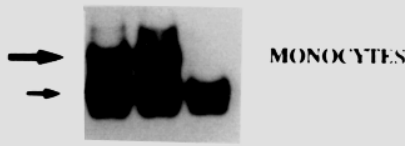

123

Figure 3. Specificity of Inhibition of DNA Binding Activity by the MAD-3 Protein

(A) Gel mobility shift analyzing various DNAbinding activities. The adenovirus major late transcription factor (MLTF) and Oct-1 (OCTA) probes (as indicated) were incubated with nuclear extracts of stimulated Jurkal T cells (lanes 1-3) plus MAD-3 programmed lysates (lane 2, WT) or plus mock-translated lysates (lane 3, MT). The class I MHC enhancer probe was incubated with a phosphocellulose fraction from HeLa cells (lane 1) containing the DNA-binding activity H2TF1 (Baldwin and Sharp, 1987) plus MAD-3 programmed lysates (lane 2, WT) or plus mock-translated lysates (lane $3, \mathrm{MT}$ )

(B) Gel mobility shift analyzing NF-KB in nuclear extracts of monocytes. The class I MHC enhancer probe was incubated with nuclear extracts of freshly isolated monocytes (lane 1). Lane 2 included the addition of mock-translated lysates (MT) and lane 3 included the addition of MAD-3 translated lysates (WT). The large arrow indicates the mobility of the NF-KB-DNA complex, and the small arrow indicates the mobility of the KBF1-DNA complex. 
A

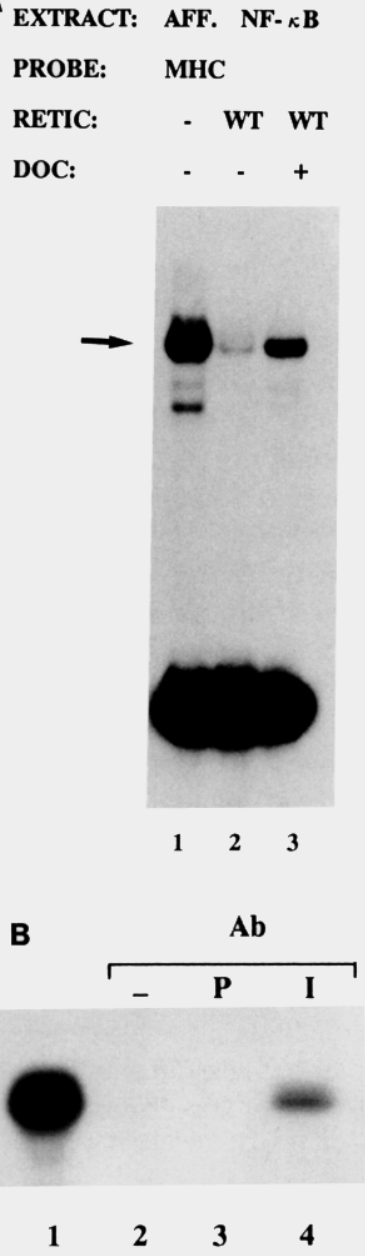

Figure 4. UIrect Interaction detween MAU-s and Nr-kB

(A) DOC releases NF- $K B$ DNA-binding activity from the MAD-3 inhibition. Gel mobility shift using the class I MHC enhancer probe with the following binding conditions: DNA affinity-purified NF-KB (lanes 1-3) plus MAD-3 programmed lysates (lanes 2 and 3). Following incubation of the purified NF-KB with the MAD-3 programmed extract, DOC was added, followed by NP-40 (lane 3). The arrow indicates the mobility of the NF-kB-DNA complex.

(B) Antibodies to NF-KB immunoprecipitate MAD-3. In vitro translated, [ ${ }^{36}$ S]methionine-labeled MAD-3 protein (lane 1) was incubated with NF-KB, followed by a no-serum control (lane 2), preimmune serum ( $P$, lane 3), or antibodies to NF-KB (I, lane 4). Reactions for lanes 2-4 were then added to protein A-Sepharose, and protein was recovered for SDS-polyacrylamide gel electrophoresis as described in the Experimental Procedures.

\section{Deoxycholate Treatment Dissociates Preformed MAD-3/NF-kB Complexes}

NF-KB is found in the cytoplasm of many uninduced cells where it is bound to $/ \mathrm{KB}$, rendering it incapable of binding DNA (Baeuerle and Baltimore, 1988a, 1988b). This cytoplasmic form of NF-KB can, however, be liberated from IKB by treatment with sodium deoxycholate (DOC), thus making it competent for DNA binding (Baeuerle and Baltimore, 1988a). We first purified NF-KB by DNA affinity chromatography to remove any potential endogenous
NF-KB-IKB complexes. As with the crude nuclear extracts of stimulated Jurkat $T$ cells (see Figure 2B), the MAD-3 translation product inhibited this partially purified NF-KB (Figure 4A, lane 2). Treatment of the NF-KB/MAD-3 reaction with sodium DOC followed by NP-40 incubation released NF-KB DNA-binding activity (Figure 4A, lane 3). Thus, the release of NF- $k B$ DNA-binding activity from the reaction is derived from NF-KB-MAD-3 complexes and not from any endogenous NF-KB-IKB in the extract. Since NF-kB DNA-binding activity can be recovered from preformed NF-KB/MAD-3 by DOC treatment, we conclude that MAD-3 encodes a protein with properties of $1 K B$.

\section{Antlbodies to NF-KB Immunoprecipitate MAD-3 \\ To determine if the translated MAD-3 protein directly inter- acts with NF-KB, an immunoprecipitation experiment was performed. The MAD-3-NF-KB complex was specifically immunoprecipitated by antibodies (Kieran et al., 1990) to the p50 DNA-binding subunit of NF-KB (Figure 4B, lane 4), but not by preimmune serum or by a no-serum control (Figure 4B, lanes 3 and 2, respectively). These results demonstrate that MAD-3 protein interacts directly with the NF-kB complex, presumably though the p65 subunit.}

\section{Discussion}

\section{MAD-3 Encodes a Protein with IKB-llke Activity}

Several characteristics of the predicted amino acid sequence encoded by the MAD-3 CDNA led us to consider whether it had properties of IKB. The first was that the protein has homology with the ankyrin repeat domain of the NF-KB/KBF1 precursor, which is in the portion of the precursor that is removed from the DNA-binding subunit (Kieran et al., 1990; Ghosh et al., 1990). The second was that the predicted ( $34 \mathrm{kd}$ ) and expressed (36-38 kd) molecular sizes of the protein are quite similar to that ( $36 \mathrm{kd}$ ) of partially purified IKB (Ghosh and Baltimore, 1990; Zabel and Baeuerle, 1990). A third was that the MAD-3 protein has several putative protein kinase consensus target sequences, and it has been demonstrated that phosphorylated IKB will not inhibit the DNA-binding activity of NF-KB (Ghosh and Baltimore, 1990; Shirakawa et al., 1989).

MAD-3 protein that was translated in vitro (see Figure 2A) specifically inhibited the DNA-binding activity of NF-KB from different sources (Figures $2 B$ and $3 B$ ). These included NF-KB activity induced by PMA and PHA treatment of Jurkat $T$ cells and constitutive NF- $\kappa B$ activity found in human monocytes. Furthermore, the DNA-binding activity of NF- $\mathrm{KB}$ induced by lipopolysaccharide and cycloheximide treatment of a mouse pre-B cell line, NF- $k B$ induced by PMA treatment of HeLa cells, and the endogenous NF-KB found in reticulocyte lysates were also inhibited by MAD-3 protein (data not shown). The specificity of the inhibition was demonstrated by the fact that other characterized DNA-binding activities are not inhibited by MAD-3 protein (Figure 3A). Furthermore, KBF1 DNA-binding activity from freshly isolated monocytes and from Jurkat cells is virtually unaffected by MAD-3 protein. Thus, the DNA- 
binding activity of NF- $\mathrm{KB}$, which is composed of $50 \mathrm{kd}$ and $65 \mathrm{kd}$ proteins (Baeuerle and Baltimore, 1989), is inhibited by the translated MAD-3 protein, whereas the DNAbinding activity of KBF1, which is apparently a homodimer of the $\mathbf{5 0} \mathbf{k d}$ subunit (Kieran et al., 1990), is not or is only weakly affected (Figures $2 B$ and $3 B$ ). These results are in agreement with previous data that demonstrate that $I \kappa B$ inhibits the DNA-binding activity of NF-kB through the 65 kd subunit (Baeuerle and Baltimore, 1989; Ghosh and Baltimore, 1990; Urban and Baeuerle, 1990; Nolan et al., 1991). Whether MAD-3 is identical to the I $\mathrm{K} B$ that has been described awaits purification of that activity and cloning of its cDNA. Furthermore, it is entirely possible that there are multiple IкB activities, possibly existing in a cell typespecific distribution. In fact, two forms of $1 \kappa B$ have been identified (Zabel and Baeuerle, 1990). In addition, it will be important to determine if MAD-3 inhibits the DNA-binding activities of other members (Ballard et al., 1990) of the rel proto-oncogene family.

\section{MAD-3 May Integrate Membrane Adhesive Interactions with the Cytoskeleton and Transcription}

Proteins bearing ankyrin repeats appear to play a prominent role in cell growth and differentiation (Lux et al., 1990). Erythrocyte ankyrins function as binding sites and anchors for integral membrane proteins, including the $\mathrm{Na}^{+}+\mathrm{K}^{+}$. ATPase and the voltage-dependent $\mathrm{Na}^{+}$channel, and brain ankyrin can bind tubulins and other proteins (discussed in Lux et al., 1990). The second domain of MAD-3 contains five tandem repeats of the ankyrin motif that have a high degree of homology to the precursor of the transcription factor KBF1/NF-kB (Kieran et al., 1990; Ghosh et al., 1990). This highly conserved motif is found in key differentiation-related genes of invertebrates, including the notch (Wharton et al., 1985), lin-12 (Yochem et al., 1988), fem-1 (Spence et al., 1990), and cdc-10 proteins (Aves et al., 1985). It has been proposed that the structure of all these proteins and their manner of expression are consistent with their being receptors or adhesive proteins involved in intracellular signaling (Lux et al., 1990). The ankyrin motif is the postulated site of association between notch and an invertebrate version of a $G$ protein $\beta$ subunit (Hartley et al., 1988).

We propose that the ankyrin repeats of MAD-3 and the $N F-\kappa B / K B F 1$ precursor form the basis for a common address for subcellular localization, bringing the two proteins into close proximity. The precise location is still open to speculation, but it seems probable from the other known functions of human ankyrins that this is likely to be associated with cytoskeletal or receptor structures. The known induction of numerous cytokine genes by cytochalasin D and colchimide-sensitive adhesion events and the rapid translocation of PKC induced by adherence (Eierman and Haskill, 1991) suggest that transcription may occur through a pathway that integrates receptor signaling and induction of specific genes through cytoskeletal-bound transcription factors.
MAD-3 May Function as a Negative Regulator of Environmental Signais in Inflammatory Macrophages and a Feedback Inhibitor

\section{in Target Tissues}

The widespread usage of NF- $\mathrm{KB}$ in transcriptional responses to cytokines (Lenardo and Baltimore, 1989) raises the concern that cells that both secrete these cytokines and can respond to the same factors would require appropriate feedback inhibition. Monocytes and epithelial cells have recently been shown to synthesize an IL-1 receptor antagonist that may serve in part to limit IL-1 responsiveness (Eisenberg et al., 1990; Haskill et al., 1991). The IKB inhibitor offers the possibility of a more pleiotropic regulator of cytokine responsiveness. The low constitutive level of MAD-3 mRNA in monocytes but the high nuclearassociated activity of NF- $\kappa B$ in these same cells suggest that monocytes in the circulation are primed for rapid NF-KB-dependent responses. Adherence leads to translocation of PKC (Eierman and Haskill, 1991), which may lead to further NF-kB nuclear localization and signaling. However, we now show that this also results in the parallel induction of the MAD-3/IKB gene, which then has the ability to down-regulate further responsiveness to mediators that transcriptionally activate other genes via NF- $\mathrm{KB}$. The rapid induction of the MAD-3 gene by adherence closely parallels that of IL-1 $\beta$ (Eierman et al., 1989) and thus provides an important potential mechanism for homeostatic regulation either through complex formation with NF- $\kappa B$ in the cytosol or through displacement of high affinity NF- $\mathrm{KB}$ bound to DNA (Zabel and Baeuerle, 1990).

\section{Experimental Procedures}

\section{Isolation of a Full-Length Version of the MAD-3 cDNA}

We have previously reported isolation of a partial MAD-3 cDNA clone, which was derived from a $\lambda$ gt 10 cDNA library produced from $30 \mathrm{~min}$ adhered monocytes (Sporn et al., 1990). Differential screening of this library had identified a series of unique clones representing immediate-early genes induced by adherence. One of these, MAD-3, was a $350 \mathrm{bp}$ fragment of a $1.6 \mathrm{~kb}$ mRNA. This partial clone was used to screen a second library constructed by Invitrogen in the pcDNA 1 vector. MRNA was derived from $30 \mathrm{~min}$ adhered monocytes and neutrophils. Screening of this library identified several apparently fulllength clones. One of these was sequenced.

DNA Sequence Analysis of cDNA Clones

Chain termination sequencing was carried out with the USB sequenase procedure employing dITP to eliminate compressions as necessary. Primers were synthesized to permit overlapping bidirectional sequencing of the entire cDNA clone.

\section{Computer Analysis}

All computer analysis and assembly of sequence information were carried out with the aid of the University of Wisconsin GCG programs. The FASTP program was used to identify the initial homology to ankyrin. Searches employing Wordsearch failed to find similar matches. GAP was used to determine the degree of homology between the NF- $\kappa B / K B F 1$ protein and the MAD-3 predicted protein sequence derived from TRANSLATE.

In Vitro Transcription and Translation of MAD-3 mRNA Two micrograms of pcDNA 1 (Invitrogen) containing full-length MAD-3 cDNA was digested with BamHI, which cuts downstream of the cDNA insert, or with Accl. The digests were phenol-chloroform extracted, ethanol precipitated, and used to synthesize RNA in a $100 \mu$ l reaction 
for $1 \mathrm{hr}$ at $37^{\circ} \mathrm{C}$ using SP6 RNA polymerase under conditions recommended by the manufacturer (Boehringer Mannheim). The RNA was extracted twice with phenol-chloroform, ethanol precipitated, and re dissolved in $20 \mu l$ of water. Synthesis of RNA was confirmed by electrophoresis of the RNA on agarose gels. Rabbit reticulocyte lysates were first depleted of an endogenous NF-kB-like DNA-binding activity. This was performed by adding $100 \mu$ of lysate to $20 \mu \mathrm{l}$ of DNA affinity resin previously washed with deionized water (see description of preparation of the resin below). The binding reaction was performed, with frequent mixing, for 10 min at room temperature. The mixture was pelleted by brief centrifugation in a microfuge and the supernatant was removed for in vitro translation reactions. Four microliters of RNA was used for in vitro translation in rabbit reticulocyte lysates following the manufacturer's (Promega Biotech) recommendations. The [ $\left.{ }^{36} \mathrm{~S}\right]$ methioninelabeled products were analyzed on a $10 \%$ SDS-polyacrylamide gel using the method of Laemmli (1970). The gel was dried and then exposed for autoradiography.

\section{Gel Mobllity Shitt Assays}

DNA-protein binding reactions were carried out in $10 \mathrm{mM}$ Tris (pH 7.7 ), $50 \mathrm{mM} \mathrm{NaCl}, 0.5 \mathrm{mM}$ EDTA, $1 \mathrm{mM}$ DTT, $2 \mu \mathrm{g}$ of poly(dl-dC) (Pharmacia), and $10 \%$ glycerol in a final volume of $20 \mu \mathrm{l}$. The reactions contained $10 \mu \mathrm{g}$ of nuclear extracts and/or $1 \mu \mathrm{l}$ of rabbit reticulocyte lysates (either programmed with MAD-3 mRNA or mock translated) and $10,000 \mathrm{cpm}$ of end-labeled MHC enhancer binding probe. p50 antiserum $(0.5 \mu \mathrm{l}$ ) (gift of Alain Israell, Pasteur institute) or $0.5 \mu \mathrm{l}$ of preimmune serum was added directly to the binding reaction. The reactions were kept at room temperature for $15 \mathrm{~min}$ and then loaded on a nondenaturing $5 \%$ polyacrylamide gel using a Tris/glycine/EDTA buffer (Baidwin, 1990); they were then electrophoresed for approximately $2 \mathrm{hr}$ at $20 \mathrm{~mA}$. The gel was then dried and autoradiographed overnight at $-70^{\circ} \mathrm{C}$.

\section{NF-KB-IKB Binding and Diseoclation Reactions}

Nuclear extracts $(10 \mu \mathrm{g})$ containing NF-KB were reacted with $1 \mu \mathrm{l}$ of MAD-3 programmed lysates or mock-translated lysates under the binding conditions described above. The reactions were kept at room temperature for $10 \mathrm{~min}$ followed by the addition of $2 \mu \mathrm{g}$ of poly(dl-dC) and $10,000 \mathrm{cpm}$ of radiolabeled DNA probe. The reactions were then loaded onto a $5 \%$ polyacrylamide Tris/glycine/EDTA gel and analyzed as described above. For the dissociation reactions, $0.8 \%$ sodium DOC was added to the binding reactions (minus poly(dl-dC) and probe) followed by $1.2 \%$ NP-40. Poly(dl-dC) and probe were added and incubated at room temperature for $15 \mathrm{~min}$. These reactions were electrophoresed and analyzed as described above.

The DNA-binding probes are labeled HindIII-EcoFI digests of pUC plasmids containing oligonucleotides cloned into the polylinker with BamHI restriction ends. Sequences are as follows: the class I MHC enhancer probe, GGCTGGGGATTCCCCATCT; the mutant MHC probe, GGCTGCGGATTCCCGATCT (Baldwin and Sharp, 1987); the major late transcription factor probe, ACCCGGTCACGTGGCCTACA the Oct-1 probe, ATGCAAAT; the IgK probe, CAGAGGGACTTTCCGAGA.

\section{Nuclear Extracts and DNA Afilnity Chromatography}

Jurkat T cells were grown in RPMI 1640 medium and $10 \%$ fetal calf serum. For stimulation of Jurkat T cells, PHA and PMA were added to final concentrations of $1 \mu \mathrm{g} / \mathrm{ml}$ and $50 \mathrm{ng} / \mathrm{ml}$, respectively. Monocytes were isolated from donors as previously described (Haskill et al., 1988). Nuclear extracts were prepared by the method of Swick et al. (1989). The DNA affinity resin contained the MHC class I enhancer sequence covalently linked to cyanogen bromide-activated Sepharose 4B (Sigma). The resin was made and the purification of NF-KB was carried out essentially by the method of Kadonaga and Tjian (1986). Nuclear extracts of PMA- and PHA-stimulated Jurkat T cells were used for the NF-kB purification. Jurkat nuclear extracts were incubated with the resin for $\mathbf{2 0} \mathrm{min}$, and NF-KB was eluted with a salt gradient. Only one round of DNA affinity chromatography was performed. Different fractions were tested for the NF-kB DNA-binding activity by gel mobility shift assays, and positive fractions were used for the DOC experiment.

\section{Immunoprecipltation of MAD-3}

The binding reactions between NF-KB and the MAD-3 product were carried out as described above. After $10 \mathrm{~min}, 2.5 \mu \mathrm{l}$ of antiserum against NF-KB (Kieran et al., 1990), preimmune serum, or $1 \times$ blinding buffer was added to the reactions and allowed to incubate for another $10 \mathrm{~min}$ at room temperature. The reactions were then added to $20 \mu \mathrm{l}$ of protein A-Sepharose beads (Sigma) preequilibrated in $1 \times$ binding buffer. After 15 min of frequent mixing, the reactions were briefly spun in a microfuge and the supernatants were removed. The beads were then washed as described (Springer, 1989), after which they were boiled for $5 \mathrm{~min}$ in $1 \times$ SDS loading buffer, briefly spun, and the supernatants run on a $10 \%$ SDS-polyacrylamide gel as described above.

\section{Acknowledgments}

The authors thank S. Sporn for isolation of the original MAD-3 clone, J. Lee and A. Peace for sequencing, D. Eierman for several RNA samples, S. Earp and J. Ting for reviewing the manuscript, B. Huckle and J. Ting for helpful discussions, J. Azizkhan for help with the figures and suggestions on presentation of data, and L. McAlister for help in the preparation of the manuscript. We gratefully acknowledge Alain Israell for the gift of the p50 antibodies. This investigation was supported by National Institutes of Health grants 1 R01 Al26774 (to S. H.), 5 T32 CA09156 (to A. D. Y.), 1 R01 CA52515 (to A. S. B.), and by a Basil O'Connor Starter Research Award from the March of Dimes Birth Defects Foundation (to A. S. B.). A. S. B. is the recipient of an American Cancer Society Junior Faculty Award (JFAA-309) and an RJR-Nabisco Scholar Award in Immunology.

The costs of publication of this article were defrayed in part by the payment of page charges. This article must therefore be hereby marked "advertisement" in accordance with 18 USC Section 1734 solely to indicate this fact.

Received April 2, 1991; revised May 30, 1991.

\section{References}

Aves, S. J., Durkacz, B. W., Carr, A., and Nurse, P. (1985). Cloning, sequencing and transcriptional control of the Schizosaccharomyces pombe cdc10 'start' gene. EMBO J. 4, 457-463.

Baeverle, P., and Baltimore, D. (1988a). Activation of DNA-binding activity in an apparently cytoplasmic precursor of the NF- $\mathrm{kB}$ transcription factor. Cell 53, 211-217.

Baeuerle, P., and Baltimore, D. (1988b). IKB: a specific inhibitor of the $N F-k B$ transcription factor. Science $242,540-546$.

Baeuerle, P., and Baltimore, D. (1989). A 65-kD subunit of active NF- $k B$ is required for inhibition of NF-KB by IKB. Genes Dev. 3, 1689-1698.

Baldwin, A. S. (1990). Analysis of sequence-specific DNA-binding proteins by the gel mobility shift assay. DNA Protein Eng. Techniques 2, 73-76.

Baldwin, A. S., and Sharp, P. A. (1987). Binding of a nuclear factor to a regulatory sequence of the mouse $\mathrm{H}-2 \mathrm{~K}^{\mathrm{b}}$ class I major histocompatibility gene. Mol. Cell. Biol. 7, 305-313.

Baldwin, A. S., and Sharp, P. A. (1988). Two transcription factors, NF-kB and H2TF1, interact with a single regulatory sequence in the class I major histocompatibility complex promoter. Proc. Natl. Acad. Sci. USA 85, 723-727.

Ballard, D. W., Walker, W. H., Doerre, S., Sista, P., Molitor, J. A., Dixon, E. P., Peffer, N. J., Hannink, M., and Greene, W. C. (1990). The $v-r e$ oncogene encodes a $\kappa B$ enhancer binding protein that inhibits NF-kB function. Cell 63, 803-814.

Bianar, M. A., Burkly, L. C., and Flavell, R. A. (1989). NF-kB binds within a region required for $B$ cell specific expression of the major histocompatibility complex class II gene $\mathrm{E}^{\mathrm{d}}$. Mol. Cell. Biol. 9, 844-846. Böhnlein, E., Lowenthal, J. W., Siekevitz, M., Ballard, D. W., Franza, B. R., and Greene, W. C. (1988). The same inducible protein(s) regulates mitogen activation of both the interleukin-2 receptor-alpha gene and type 1 HIV. Cell 53, 827-836.

Bours, V., Villalobos, J., Burd, P., Kelly, K., and Siebenlist, U. (1990). Cloning of a mitogen-inducible gene encoding a $K B$ DNA-binding activ- 
ity with homology to the rel oncogene and to cell-cycle motifs. Nature 348, 76-80.

Cantley, L. C., Auger, K. R., Carpenter, C., Duckworth, B., Graziani, A., Kapeller, R., and Soltoff, S. (1991). Oncogenes and signal transduction. Cell 64, 281-302.

Caput, D., Buetler, B., Hartog, K., Thayer, A., Brown-Shimer, S., and Cerami, A. (1986). Identification of a common nucleotide sequence in the $3^{\prime}$-untranslated region of mRNA molecules specifying inflammatory mediators. Proc. Natl. Acad. Sci. USA 83, 1670-1674.

Carthew, R. W., Chodosh, L. A., and Sharp, P. A. (1985). An RNA polymerase II transcription factor binds to an upstream element in the adenovirus major late promoter. Cell 43, $439-448$.

Eierman, D. F., and Haskill, S. (1991). $\beta 1$ and $\beta 2$ integrin subunit regulation of the monocyte and inflammatory response. In International Conference on Leukocyte Biology, M. Meltzer and A. Mantovani, eds. (New York: John Wiley \& Sons, Inc.), in press.

Eierman, D. F., Johnson, C. E., and Haskill, J. S. (1989). Human monocyte inflammatory mediator gene expression is selectively regulated by adherence substrates. I. Immunol. 142, 1970-1976.

Eisenberg, S. P., Evans, R. J., Arend, W. P., Verderber, E., Brewer, M. T., Hannum, C. H., and Thompson, R. C. (1990). Primary structure and functional expression from complementary DNA of a human interleukin 1 receptor antagonist. Nature 343, 341-346.

Fan, C.-M., and Maniatis. T. (1989). Two different virus-inducible elements are required for human $\beta$-interferon gene regulation. EMBO J. $8,101-110$.

Ghosh, S., and Baltimore, D. (1990). Activation in vitro of NF-кB by phosphorylation of its inhibitor, IкB. Nature 344, 678-682.

Ghosh, S., Gifford, A. M., Riviere, L. R., Tempst, P., Nolan, G. P., and Baltimore, D. (1990). Cloning of the p50 DNA binding subunit of NF- $\kappa B$ : homology to rel and dorsal. Cell 62, 1019-1029.

Hartley, D. A., Preiss, A., and Artavanis-Tsakonas, S. (1988). A deduced gene product from the Drosophila neurogenic locus, Enhancer of split, shows homology to mammalian G-protein $\beta$ subunit. Cell 55 , 785-795.

Haskill, S., Johnson, C., Eierman, D., Becker, S., and Warren, K. (1988). Adherence induces selective mRNA expression of monocyte mediators and proto-oncogenes. J. Immunol. 140, 1690-1694.

Haskill, S., Peace, A., Morris, J., Sporn, S. A., Martin, G., Ralph, P., Smith, T., Anisowicz, A. Lee, S., and Sager, R. (1990). Identification of three related human GRO genes encoding cytokine functions. Proc. Natl. Acad. Sci. USA 87, 7732-7736.

Haskill, S., Martin, G., Van Le, L., Morris, J., Peace, A., Bigler, C. F., Jaffe, G. J., Hammerberg, C., Sporn, S. A., Fong, S., Arend, W. P., and Ralph, P. (1991). cDNA cloning of an intracellular form of the human interleukin 1 receptor antagonist associated with epithelium. Proc. Natl. Acad. Sci. USA 88, 3681-3685.

Israël, A., Le Bail, O., Hatat, D., Piette, J., Kieran, M., Logeat, F., Wallach, D., Fellous, M., and Kourilsky, P. (1989). TNF stimulates expression of MHC class I genes by inducing an NF- $\kappa B$-like enhancer binding activity which displaces constitutive factors. EMBO J. 8, 37933800 .

Kadonaga, J., and Tjian, R. (1986). Affinity purification of sequencespecific DNA binding proteins. Proc. Natl. Acad. Sci. USA 83, 58895893.

Kieran, M., Blank, V., Logeat, F., Vandekerckhove, J., Lottspeich, F., Le Bail, O., Urban, M. B., Kourilsky, P., Baeuerle, P. A., and Israël, A. (1990). The DNA binding subunit of NF-KB is identical to factor KBF1 and homologous to the rel oncogene product. Cell 62, 1007-1018.

Kozak, M. (1989). The scanning model for translation: an update. J. Cell Biol. 108, 229-241.

Laemmli, U. (1970). Cleavage of the structural proteins during assembly of the head of bacteriophage T4. Nature 227, 680-685.

Lenardo, M. J., and Baltimore, D. (1989). NF-kB: a pleiotropic mediator of inducible and tissue-specific gene control. Cell 58, 227-229.

Lenardo, M. J., Fan, C.-M., Maniatis, T., and Baltimore, D. (1989). The involvement of NF- $\mathrm{KB}$ in $\beta$-interferon gene regulation reveais its role as a widely inducible mediator of signal transduction. Cell $57,287-$ 294.
Liebermann, T., and Baltimore, D. (1990). Activation of IL-6 gene expression through the NF-кB transcription factor. Mol. Cell. Biol. 10, 2317-2324

Lowenthal, J., Ballard, D., Bogerd, H., Bohnlein, E., and Greene, W. (1989). Tumor necrosis factor-alpha activation of the IL-2 receptoralpha gene involves the induction of $\kappa B$-specific DNA binding proteins. J. Immunol. 142, 3121-3128.

Lux, S. E., John, K. M., and Bennett, V. (1990). Analysis of cDNA for human erythrocyte ankyrin indicates a repeated structure with homology to tissue-differentiation and cell-cycle control proteins. Nature 344 , 36-42.

Meyer, R., Hatada, E. N., Hohmann, H.-P., Haiker, M., Bartsch, C., Rothlisberger, U., Lahm, H.W., Schlaeger, E. J., van Loon, A. P. G. M., and Scheidereit, C. (1991). Cloning of the DNA-binding subunit of human nuclear factor $\kappa B$ : the level of its mRNA is strongly regulated by phorbol ester or tumor necrosis factor $\alpha$. Proc. Natl. Acad. Sci. USA 88, 966-970.

Nabel, G. J., and Baltimore, D. (1987). An inducible transcriptional factor activates expression of human immunodeficiency virus in $T$ cells. Nature 326, 711-713.

Nolan, G. P., Ghosh, S., Liou, H.-C., Tempst, P., and Baltimore, D. (1991). DNA binding and IKB inhibition of the cloned p65 subunit of NF- $\mathrm{B}$, a rel-related polypeptide. Cell 64, 961-969.

Noland, T. A., Raynor, R. L., and Kuo, J. F. (1989). Identification of sites phosphorylated in bovine cardiac troponin I and troponin $T$ by protein kinase $C$ and comparative substrate activity of synthetic peptides containing the phosphorylation sites. J. Biol. Chem. 264, 2077820785.

Osborn, L., Kunkel, S., and Nabel, G. J. (1989). Tumor necrosis factor $a$ and interleukin 1 stimulate the human immunodeficiency virus enhancer by activation of the nuclear factor $\kappa B$. Proc. Natl. Acad. Sci. USA $86,2336-2340$.

Rogers, S., Wells, R., and Rechsteiner, M. (1986). Amino acid sequences common to rapidly degraded proteins: the PEST hypothesis. Science 234, 364-368.

Ron, D., Brasier, A., Wright, K., Tate, J., and Habener, J. (1990). An inducible 50-kilodalton NF- $\kappa \mathrm{B}$-like protein and a constitutive protein both bind the acute-phase response element of the angiotensinogen gene. Mol. Cell. Biol. 10, 1023-1232.

Ruben, S., Dillon, P., Schreck, R., Henkel, T., Chen, C.-H., Maher, M. Baeuerle, P., and Rosen, C. (1991). Isolation of a rel-related human CDNA that potentially encodes the $65 \mathrm{kd}$ subunit of NF-KB. Science $251,1490-1493$.

Sen, R., and Baltimore, D. (1986). Multiple nuclear factors interact with the immunoglobulin enhancer sequences. Cell 46, 705-716.

Shaw, G., and Kamen, R. (1986). A conserved $A U$ sequence from the 3' untranslated region of GM-CSF mRNA mediates selective mRNA degradation. Cell 46, 659-667.

Shimizu, H., Mitomo, K., Watanabe, T., Okamoto, S., and Yamamoto, K.-I. (1990). Involvement of a NF-KB like transcription factor in the activation of the interleukin- 6 gene by inflammatory lymphokines. Mol. Cell. Biol. 10, 561-568.

Shirakawa, F., and Mizel, S. (1989). In vitro activation and nuclear translocation of NF-kB catalyzed by CAMP-dependent protein kinase and protein kinase $C$. Mol. Cell. Biol. 9, 2424-2430.

Shirakawa, F., Chedid, M., Suttles, J., Pollock, B., and Mizel, S. (1989). Interteukin 1 and CAMP induce $\mathrm{K}$ immunoglobulin light-chain expression via activation of an NF-kB-like DNA-binding protein. Mol. Cell. Biol. 9, 959-964.

Singh, H., Sen, R., Baltimore, D., and Sharp, P. A. (1986). A nuclear factor that binds to a conserved sequence motif in transcriptional control elements of immunoglobulin genes. Nature 319, 154-158.

Spence, A. M., Coulson, A., and Hodgkin, J. (1990). The product of fem-1, a nematode sex-determining gene, contains a motif found in cell cycle control proteins and receptors for cell-cell interactions. Cell $60,981-990$.

Sporn, S. A., Eierman, D. F., Johnson, C. E., Morris, J., Martin, G., Ladner, M., and Haskill, S. (1990). Monocyte adherence results in 
selective induction of novel genes sharing homology with mediators of inflammation and tissue repair. J. Immunol. 144, 4434-4441.

Springer, T. (1989). Immunoprecipitation. In Current Protocols in Molecular Biology, F. Ausubel, R. Brent, R. Kingston, D. Moore, J. Seidman, J. Smith, and K. Struhl, eds. (New York: Greene Publishing Associates and Wiley-Interscience), pp. 16.1-16.9.

Swick, A., Blake, M., Kahn, J., and Azizkhan, J. (1989). Functional analysis of GC element binding and transcription in the hamster dihydrofolate reductase gene promotor. Nucl. Acids Res. 17, 9291-9304.

Urban, M., and Baeverle, P. (1990). The $65 \mathrm{kD}$ subunit of NF-KB is a receptor for $1 \kappa B$ and a modulator of DNA-binding specificity. Genes Dev. 4, 1975-1984.

Visvanathan, K. V., and Goodbourn, S. (1989). Double-stranded RNA activates binding of NF-kB to an inducible element in the human betainterferon promoter. EMBO J. 8, 1129-1138.

Wharton, K. A., Johansen, K. M., Xu, T., and Artavanis-Tsakonas, S. (1985). Nucleotide sequence from the neurogenlc locus Notch implies a gene product that shares homology with proteins containing EGF-like repeats. Cell 43, 567-581.

Yochem, J., Weston, K., and Greenwald, I. (1988). The Caenorhabditis elegans lin-12 gene encodes a transmembrane protein with overall similarity to Drosophila Notch. Nature 335, 547-550.

Zabel, U., and Baeuerle, P. A. (1990). Purified human IKB can rapidly dissociate the complex of NF.KB transcription factor with its cognate DNA. Cell 61, 255-265.

\section{GenBank Accession Number}

The accession number for the sequence reported in this paper is M69043. 